\title{
An innovative solution for drying municipal waste in the process of producing alternative fuel on the example of the Municipal Waste Management Company in Olsztyn - a case study
}

\author{
Jolanta Fieducik ${ }^{1}$ \\ ${ }^{1}$ University of Warmia and Mazury in Olsztyn, Faculty of Technical Sciences, Poland
}

\begin{abstract}
This article presents an innovative solution for drying waste in bioreactors on the example of the Municipal Waste Treatment Plant (ZUOK) in Olsztyn. Shredded mixed waste undergoes fermentation in bioreactors and produces heat for waste drying. Waste transported to the plant is divided into sorted waste which is recycled and mixed waste which is processed into different size fractions. Processed waste is used in the production of alternative fuel which can be burned in dedicated systems in cement plants or incineration plants. Around $5-15 \%$ of waste cannot be processed and is landfilled.
\end{abstract}

\section{Innovative waste drying in bioreactors}

The Municipal Waste Treatment Plant in Olsztyn (ZUOK) has been commissioned for use in 2015. An innovative solution for drying waste without the involvement of external energy sources has been implemented in the plant. The biological waste treatment system in the Olsztyn plant has a processing capacity of $125,000 \mathrm{Mg} /$ year. Waste is transported to the plant from 37 municipalities in the Region of Warmia and Mazury. Untreated waste has an estimated moisture content of $45 \%$. Waste is dried in 14 bioreactors $[1,2]$.

\footnotetext{
${ }^{1}$ Corresponding author: jolanta.fieducik@uwm.edu.pl
} 


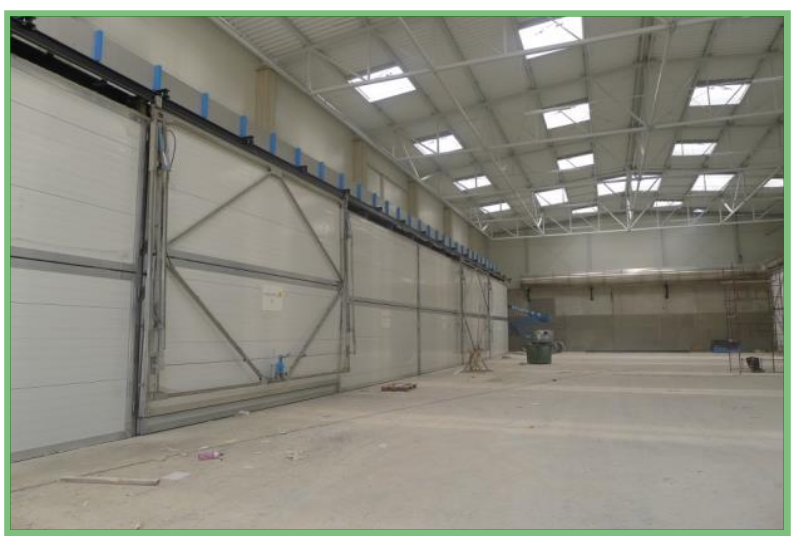

Fig. 1. Bioreactor - a biological waste drying chamber.

Every bioreactor measures $33 \mathrm{~m}$ in length, $7 \mathrm{~m}$ in width, and $5.5 \mathrm{~m}$ in height.

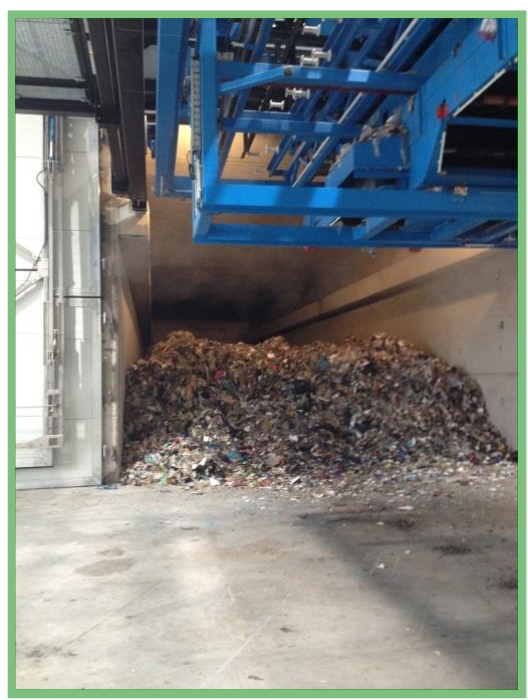

Fig. 2. Interior of a biological drying chamber.

Waste stored in the mixed waste collection point (PPO) is transported to a bioreactor by a system of conveyor belts and an automatic loading system which ensures that the accumulated waste is evenly distributed without densely compacted zones that prevent air flow. Every bioreactor can accommodate $160-300 \mathrm{Mg}$ of waste, depending on its specific weight and loading conditions [2].

Biological drying chambers are equipped with aeration floors, tunnel fans and temperature sensors. The biological drying process lasts 7 to 14 days [1]. Waste is dried to a moisture content of $10-20 \%$.

The waste drying process in the bioreactor proceeds in the following stages:

- waste stored in the mixed waste collection point (PPO) is transported to bioreactors,

- the bioreactor gate is closed when the bioreactor is completely filled with waste, and the biological drying process is initiated, 
- in the first stage of the process, the temperature inside the bioreactor is brought to an optimal level $\left(60-80^{\circ} \mathrm{C}\right)$ to generate sufficient amounts of heat for evaporating moisture from waste. The optimal temperature is achieved without the involvement of external energy sources through a series of biological processes inside the waste bed [3].

- the biological drying process begins after 1-3 days of heat generation. Heat generated in the first stage of the process (in a different reactor) and heat generated in a given reactor is used to evaporate moisture from waste,

- during biological drying, temperature is maintained at around $50-70^{\circ} \mathrm{C}$ for $4-5$ days, after which it decreases to around $30^{\circ} \mathrm{C}-40^{\circ} \mathrm{C}$. The decrease in temperature indicates that the energy-generating potential of waste has been depleted and that the biological drying process is complete.

The biological drying process with temperature and moisture content curves is presented in Figure 3.

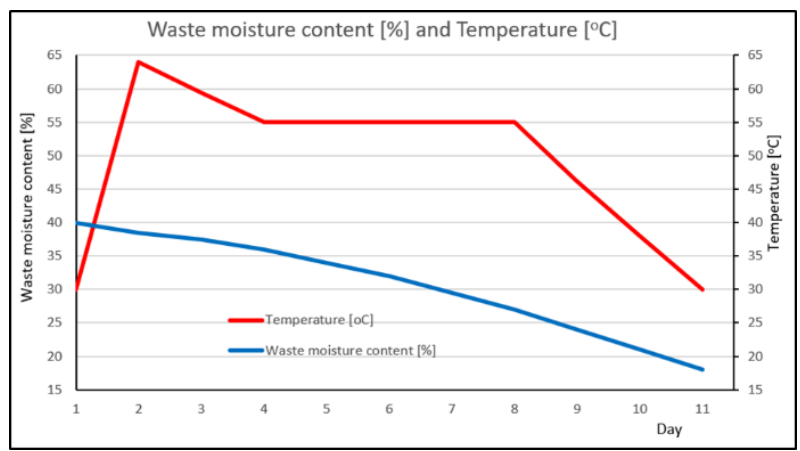

Fig. 3. Parameters of the biological drying process.

Biological drying decreases the moisture content of waste to $10-20 \%$. The weight of decomposed and dehydrated waste is reduced by around $30 \%$. The decomposition of waste organic matter generates heat. In heat exchangers, air is heated by exhaust air, and it is used for waste drying in bioreactors. After 7-14 days, dried waste is unloaded from bioreactors and transported to the mechanical waste treatment station (SMP) [1].

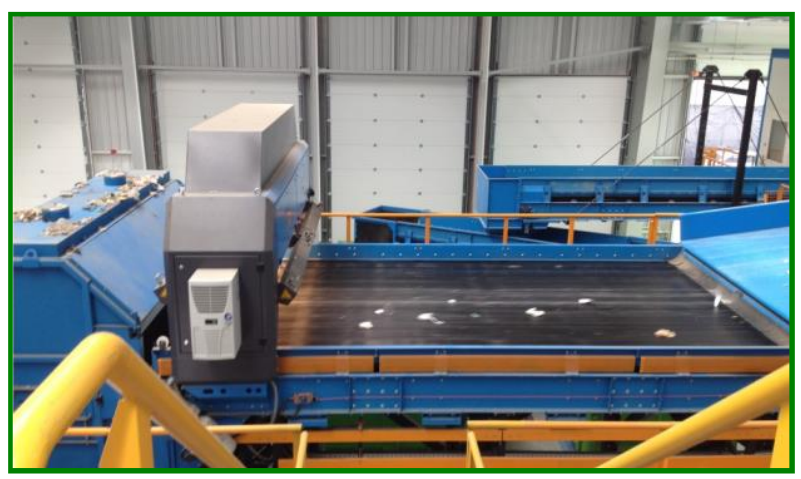

Fig. 4. Mechanical waste treatment station. 
1. The biological drying system is composed of the following elements:

2. Biological drying chamber

3. Dried waste

4. Aeration floor

5. Drainage system (for evacuating process water)

6. Chamber gate

7. Pressure chamber
8. Main fresh air duct

9. Main exhaust air duct

10. Recirculation module

11. Heat exchanger (2 units)

12. Fan

13. Temperature sensor

14. Ceiling

15. Insulation

16. Inspection hatch

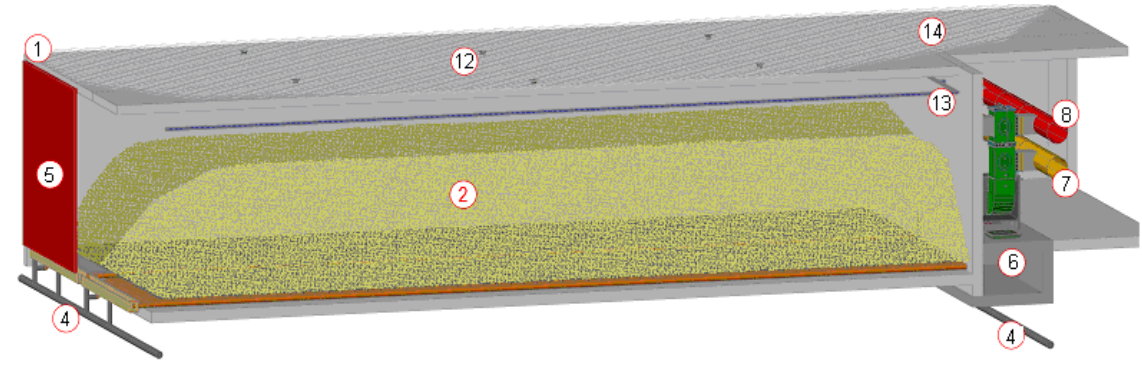

Fig. 5. Cross-section of a biological drying chamber.

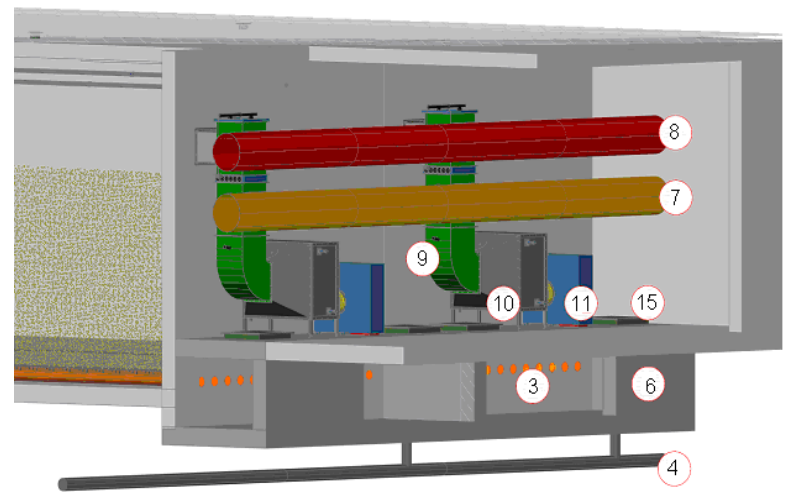

Fig. 6. Rear view of a biological drying chamber.

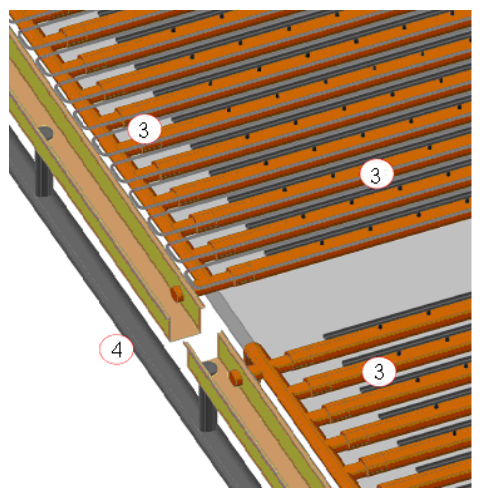

Fig. 7. Structure of a biological drying chamber, aeration system and drainage system. 


\section{Drying process}

The aeration system supplies air of the required quality and quantity for a given process. Fresh air for drying is drawn from the mixed waste collection point (PPO) and the mechanical treatment station (SMP). Every drying chamber has its own aeration system which can be operated and controlled independently of other bioreactors in every phase of the drying process. The aeration system supplies up to $20 \mathrm{~m}^{3} / \mathrm{h}$ of air per $1 \mathrm{~m}^{3}$ of waste.

All chambers are connected to two main air ducts. The fresh air duct supplies air to drying chambers, and the exhaust air duct evacuates air from chambers to the scrubbing system. The main ducts are connected to an air recirculation module. Air flows through the recirculation module depending on drying requirements. The biological drying process is monitored, and parameters such as waste temperature, oxygen content and water removal are controlled based on the measured temperature and air volume. Fresh air for drying is drawn from the ventilation system in the waste collection point, mechanical treatment station, packaging waste sorting line and local air intakes in the maneuvering area of the biological treatment station. Exhaust air is evacuated from chambers via an opening in the rear wall. Heat can be recovered from exhaust air in the recirculation module, depending on process requirements.

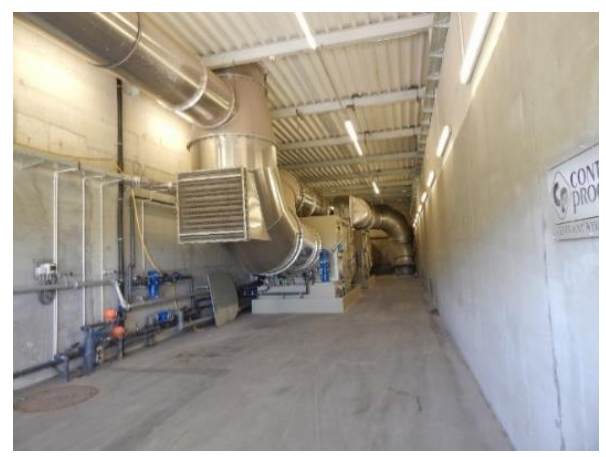

Fig. 8. Air supply system.

Negative pressure is maintained to minimize odor emission from drying chambers. The quantity of supplied air is determined based on the progress of drying in every chamber. Process parameters are stored and adjusted by the control system. To minimize odor emissions during chamber filling and emptying, air is evacuated from every chamber by the exhaust air duct via an opening in the rear wall.

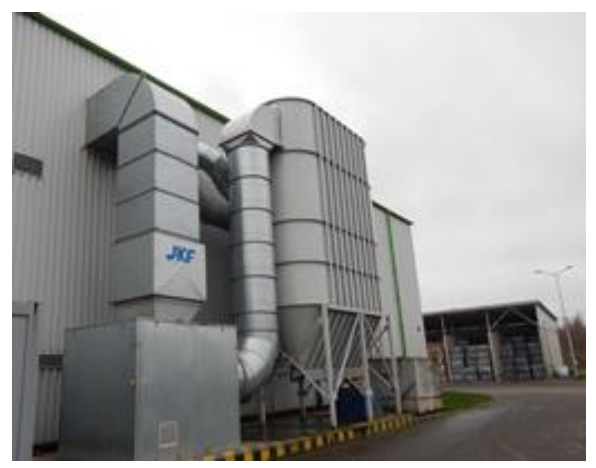

Fig. 9. Air scrubbing system. 
Exhaust air evacuated from the biological drying system and the main hall is purified in two chemical scrubbers and a biofilter before it is released into the ambient.

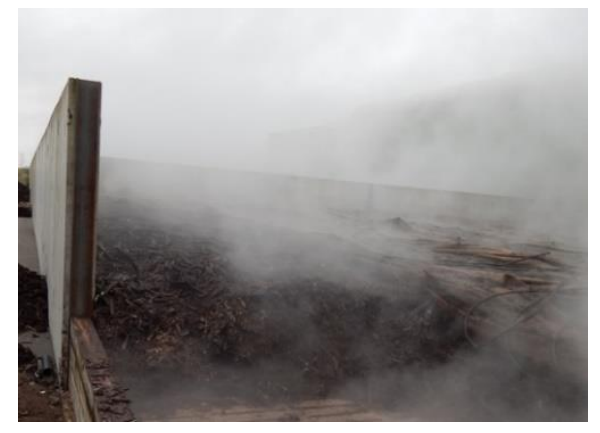

Fig. 10. Air scrubbing in a biofilter bed.

The air scrubbing system consists of three main elements:

- A pumping system composed two fans which pump air from chemical scrubbers to the biofiltration bed.

- Chemical scrubbers protect microorganisms colonizing the biofiltration bed against the adverse influence of hot air from biodrying chamber. The scrubbers adjust the moisture content of air before it reaches the biofilter and remove ammonia from exhaust air by applying sulfuric acid.

- The biofilter is the main element of the air scrubbing system which biodegrades odorous compounds in exhaust air. The biofilter relies on the natural ability of microorganisms to neutralize toxic and odorous compounds in exhaust air.

The aeration system is equipped with two heat exchanges to maximize heat recovery from the biodrying process. Excess heat from preliminary biodrying in chambers 1-7 is transported by heat exchangers and the water circulation system and used to heat fresh air in chambers 8-14. This solution contributes to the drying process in chambers 8-14. Biodrying chambers have aeration floors which are responsible for the even distribution of air during the biodrying process. The plant has a wastewater evacuation system. Biological waste treatment produces two types of wastewater:

- leachate from biodrying chambers,

- scrubber effluent wastewater.

Wastewater produced by biodrying chambers is evacuated via the drainage system and evacuated to the process sewage system. Exhaust air cooling leads to condensation. Water vapor condensed in heat exchangers is used to adjust the moisture content of waste during biological drying. The process is controlled by the PLC Siemens S7 programmable controller.

\section{Production of alternative fuel}

Various definitions of alternative fuel are presented below.

According to standard EN-15359:2005 - Solid recovered fuels. Specification and classes, alternative fuel is defined as fuel with standardized qualitative parameters (e.g. calorific value, chlorine content, mercury content) generated only from waste other than hazardous waste and used as a source of energy in waste combustion or co-combustion [4].

In Poland, alternative (secondary, substitute) fuel is defined as comminuted and uniformly mixed combustible waste, generated in the process of combining non-hazardous 
waste, with or without solid fuels, liquid fuels or biomass, whose incineration does not exceed the emission standards stipulated by the Regulation of the Minister of the Environment on emission standards for waste co-incineration systems. Alternative fuel has been assigned waste code 191210 (combustible waste - refuse derived fuel), and it is classified as a waste product [5].

In the 2003 report of the European Commission entitled "Refuse derived fuel, current practice and perspectives", alternative fuel is defined as refuse-derived fuel (RDF) which has been processed for industrial needs and is characterized by high calorific value. Refuse derived fuel includes high calorific fractions from processed municipal waste, industrial waste, commercial waste, wastewater sediments, hazardous industrial waste and biomass.

Alternative fuels supplied for industrial purposes should meet the following requirements:

- Moisture content $<20 \%$,

- Calorific value $>15 \mathrm{MJ} / \mathrm{kg}$,

- Sulfur content $<1 \%$.

Ash content is not defined due to the specific nature of refuse derived fuel.

Biologically dried waste is transported from the drying chamber to the dosing buffer which feeds waste in a uniform and continuous manner to the treatment line. Dried waste is processed in an electromagnetic separator which recovers ferrous metals and aluminum, and deposits them in the appropriate containers. After metal recovery, the waste stream is directed to a ballistic separator which removes the light combustible fraction and the heavy fraction of inorganic residual waste from the feed stream. The combustible fraction is used directly in RDF production.

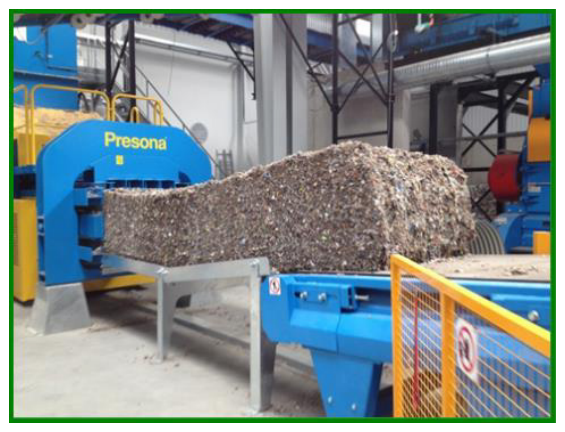

Fig. 11. Produced alternative fuel.

Refuse-derived fuel is purified in the light fraction separation line. PVC waste can be removed from the light fraction to reduce the chlorine content of RDF. In the ballistic separator, waste is directed to a vibrating trough which removes the high calorific fraction and inorganic residual waste. The high calorific fraction is transported to the RDF purification line, and inorganic residual waste is fed to the inorganic residual waste collection system $[6,7]$.

The minimum processing capacity of the Municipal Waste Treatment Plant in Olsztyn is $45,000 \mathrm{Mg}$ of RDF per year. Alternative fuel can be used in the following facilities:

- municipal waste incineration plants where waste can be co-incinerated with alternative fuel,

- power generating waste incineration plants which run only on alternative fuel,

- cement plants where fossil fuels can be partially substituted with alternative fuel,

- steam boilers. 
- The following types of municipal waste are processed into RDF in ZUOK Olsztyn:

- plastic,

- paper and cardboard,

- sawdust and wood waste,

- textiles,

- rubber,

- biodegradable

- fraction of municipal waste.

The Municipal Waste Treatment Plant in Olsztyn acquired an integrated environmental permit based on the quantity of waste processed by different systems during a 12-month trial period:

- mixed waste treatment (PPO/SBP/SMP) - 125,000 Mg/year,

- packaging waste sorting (SOO) - $16,000 \mathrm{Mg} /$ year,

- storage and treatment of bulk waste (DOW) - 5,000 Mg/year,

- storage and treatment of construction debris (IPOB) - 5,000 Mg/year.

The alternative fuel produced by the plant has the following parameters:

- Calorific value - $16 \mathrm{MJ} / \mathrm{kg}$,

- Average moisture content - 17\%,

- Average density $-150 \mathrm{~kg} / \mathrm{m}^{3}$,

- Average chlorine content $-0.7 \%$,

- Content of inorganic residual waste - around 5\%.

\section{Conclusions}

The Municipal Waste Treatment Plant in Olsztyn has been in operation for two years, and its performance indicates that it is a worthwhile investment. The parameters of alternative fuel produced in ZUOK in Olsztyn suggest that the plant has fully met its operating goals:

- In the future, alternative fuel can supply heat generation plants,

- Municipal waste is the only type of fuel with a positive result in a cost-benefit analysis.

- Modern waste incineration plants are far less harmful for the environment that combined heat and power plants burning fossil fuels.

- Public campaigns promoting waste sorting at the source are needed to minimize the quantity of mixed waste that requires further treatment.

\section{References}

1. Design and construction of the Municipal Waste Treatment Plant in Olsztyn. Detailed structural design developed by Górnicze Biuro Projektów PANGAZ

2. Source materials from the Municipal Waste Treatment Plant in Olsztyn

3. Cz. Rosik - Dulewska, Basics of waste management, PWN Warsaw (2000)

4. A. Błędzki, R. Jeziórska, J. Kijeński, Recovery and recycling of polymeric materials, PWN Scientific Publisher, Warsaw, 1, (2017)

5. K. Karpus, B. Rakoczy, The Waste Act. Wolters Kluwer, (2016)

6. M. Ulewicz, J.Siwka, Processes of recovery and recycling of selected materials Ed. Czestochowa University of Technology, Częstochowa (2010)

7. W. Kotowski, R. Przywarska, The basics of recovery, recycling and waste disposal (Ed. School of Economics and administration in Bytom, Bytom 2004) 